\title{
Fulminant Citrobacter Meningitis With Multiple Periventricular Abscesses in a Three-Month-Old Infant
}

\author{
P. Anoop, M. A. Anjay, Johny Vincent and B. Girija
}

Institute of Maternal and Child Health, Medical College, Calicut, Kerala, India

\begin{abstract}
Citrobacter, a Gram-negative enteric bacillus, is a rare cause of septicemia and meningitis, seldom reported beyond the neonatal period. It is characterized by a fulminant clinical course and a high incidence of complications, including brain abscesses. We studied a three-month-old infant with Citrobacter meningitis, who developed acute communicating hydrocephalus and multiple periventricular brain abscesses while on treatment. The patient died, despite intensive antibiotic treatment directed towards the causative organism, C. diversus.
\end{abstract}

Key Words: Citrobacter, meningitis, brain abscess.

Despite considerable advances in antimicrobial therapy, bacterial meningitis continues to be a major cause of pediatric morbidity and mortality, particularly in infants. The substantial reduction in cases of Haemophilus influenza meningitis, following successful immunization campaigns, has helped focus attention on other, less frequent causative agents. Rarely diagnosed organisms are known to produce meningitis in vulnerable groups and can confound standard therapeutic approaches.

Citrobacter is a normal inhabitant of the human intestine. The generic term was proposed by Werkman and Gillen in 1931. The genus consists of three different species. One of them, C. diversus (C.koseri), is a rare cause of sporadic and epidemic meningitis, with a high incidence of brain abscesses. There are occasional reports of Citrobacter meningitis in neonates, though it has seldom been reported from the tropics. We report an older infant with Citrobacter meningitis, who had a fulminant course of disease, complicated by hydrocephalus and multiple brain abscesses.

Received on 23 January 2003; revised 01 September 2003. Address for correspondence: Dr. P. Anoop. B-31, “ANUPAMA”, North Girinagar, Kadavanthra PO, Kochi - 682 020,Kerala state, India.Phone : 91484 2206255.E-mail: dranoopp@ rediffmail.com

The Brazilian Journal of Infectious Diseases 2003;7(6):429-432 (C) 2003 by The Brazilian Journal of Infectious Diseases and Contexto Publishing. All rights reserved.

\section{Case Report}

A 92-day-old male infant was admitted with a history of fever, vomiting and incessant crying since three days of age. He was feeding poorly and was lethargic, with two episodes of generalized tonic clonic seizures on the day of admission. Delivered at term, with a birth weight of 3,200 grams, he had been asymptomatic till this illness began.

Clinical evaluation revealed a sick febrile infant, with a bulging anterior fontanel and no sutural separation. There were no obvious congenital anomalies, infection foci, or focal neurological deficits. A lumbar puncture was made and two drops of thick pus were obtained. A Gram stain of the specimen revealed Gram-negative bacilli. He was immediately started on an initial empirical antimeningitis treatment of ampicillin $400 \mathrm{mg} / \mathrm{kg} /$ day and ceftriaxone $100 \mathrm{mg} / \mathrm{kg} /$ day, as per standard institutional protocols, pending the results of blood and cerebrospinal fluid (CSF) cultures. A full blood count gave a leukocyte count of 4,600 cells $/ \mathrm{mm}^{3}$, with a differential of $40 \%$ neutrophils and $54 \%$ lymphocytes. The erythrocyte sedimentation rate was $80 \mathrm{~mm} / 1^{\text {st }}$ hour and the C-reactive protein was elevated.

The bacterial culture of CSF produced smooth, convex colonies of Gram-negative bacilli on nutrient agar. The bacilli were motile, gas producing and late lactose fermenting. The citrate utilization test was 
positive. These characteristic features pointed to Citrobacter as the etiological agent. The species identification of $C$. diversus was made on the basis of indole and adonitol positivity, hydrogen sulphide negativity and utilization of malonate. The antibiogram revealed sensitivity to gentamicin, cefotaxime and ceftriaxone, with resistance to ampicillin and trimethoprim. The blood culture was sterile.

The patient deteriorated during the first two days, with deep coma and occasional decerebrate posturing. On receiving the bacterial sensitivity report, ampicillin was substituted by gentamicin, and ceftriaxone was continued. A computed tomography (CT) scan of the head revealed a grossly dilated ventricular system, with ventriculitis, multiple (six) brain abscesses and a thinned out cortical mantle (Figure 1). Four of the abscesses communicated with the ventricles. Because of the fulminant clinical course, and the lack of adequate response to therapy, lumbar puncture was repeated on the fourth day. Turbid CSF was tapped, with a leukocyte count of $3,600 / \mathrm{mm}^{3}$, of which $70 \%$ were neutrophils; CSF protein was elevated to $900 \mathrm{mg} / \mathrm{dl}$ and the CSF sugar was $50 \mathrm{mg} / \mathrm{dl}$, while the concurrent blood sugar was $110 \mathrm{mg} / \mathrm{dl}$. Cultures were sterile.

The sensorium improved over the next few days and seizures were partially controlled. But the head circumference increased by one centimeter during the first week in the hospital. Antibiotics and supportive measures were continued, along with decompression of the abscesses and serial ventricular taps. Intraventricular gentamicin was administered at a dose of $5 \mathrm{mg} / \mathrm{kg}$ on the $10^{\text {th }}$ and $12^{\text {th }}$ days. Despite these measures he succumbed to the illness on the $13^{\text {th }}$. Tests to detect any underlying immunodeficiency, including HIV screening of the mother and estimation of serum complement levels of the infant, were non-contributory.

\section{Discussion}

The genus Citrobacter consists of three species, namely $C$. freundii, $C$. amalonaticus and $C$. diversus (C. koseri). Among these, $C$. diversus is a particularly devastating, albeit rare, cause of neonatal meningitis. Central nervous system infection with this organism produces multiple brain abscesses, at an unusually high frequency [1]. Whereas it is almost exclusively an opportunistic pathogen in older children, the reasons for the enhanced virulence of Citrobacter in early infancy and its propensity to produce multiple brain abscesses are unexplained [2]. Pathogenic mechanisms, like cerebral vasculitis, infarction and invasion of the necrotic tissue by the bacteria, are believed to be responsible for the frequent complications [3].

Citrobacter meningitis is unique in that its course is characterized by a high incidence of periventricular brain abscesses, which occurred in this infant as well [4]. In an extensive review by Graham and Band, $77 \%$ of the cases of Citrobacter meningitis were found to result in intracerebral abscesses [1]. This is in striking contrast to non-Citrobacter Gram-negative meningitis, the incidence of which was found to be as low as $10 \%$ [1]. There have been several documented instances of epidemic, sporadic and nosocomial neonatal sepsis by this organism. In 1973, four cases of neonatal Citrobacter meningitis were reported from a single premature baby unit within a period of six months [5]. There is evidence that $C$. diversus can persist in the brain, as suggested by a case report of recovery of this organism from the CSF during a neurosurgical procedure four years after an episode of neonatal meningitis [6].

Generic and specific identification is based on the typical morphology, growth pattern and biochemical reactions. An antigenic scheme comprised of 14 different subtypes, with serological and biochemical characterization of each subtype, has been attempted [7].

Most Citrobacter strains are reported to be resistant to ampicillin, reaching as high as $97 \%$ in one series [8]. However, almost all were sensitive to aminoglycosides and third generation cephalosporins. Such was the case with this infant also. Once the organism is identified, the standard treatment is an intravenously administered third or fourth generation cephalosporin, with or without an aminoglycoside [9]. The suggested alternative drugs are meropenem and trimethoprim/sulfamethoxazole [9]. Due to the poor meningeal penetration of aminoglycosides, intrathecal 
Figure 1. A large abscess $(\mathrm{A})$ in the right parietal lobe, communicating with the dilated frontal horn of the lateral ventricle (FLV). Also note the dilated third ventricle (3 V) and the occipital horns of the lateral ventricles (OLV).

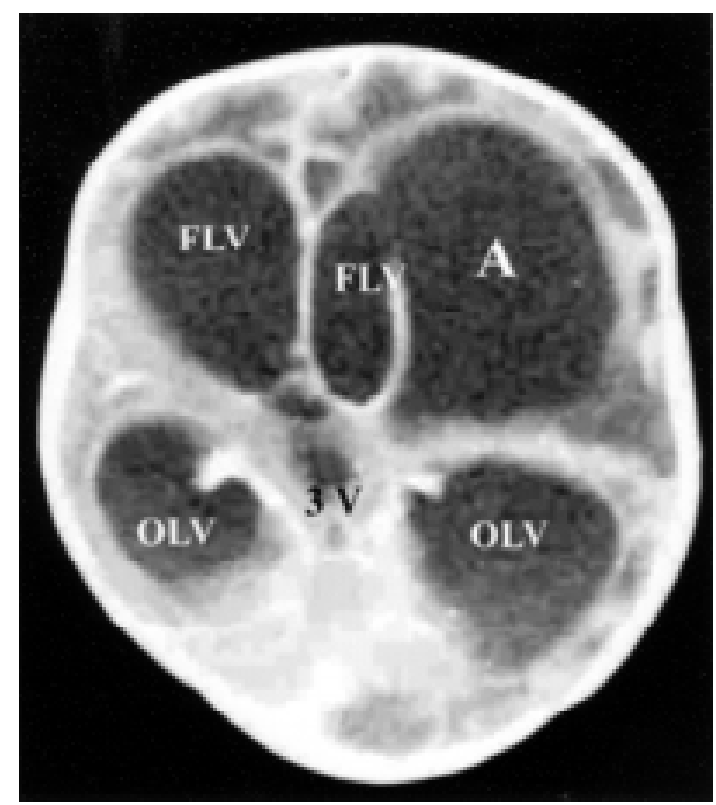

and intraventricular gentamicin have been tried in individual cases, but this is not routinely recommended [10]. Considering the paucity of definitive data in this regard, the unusual etiology and the fulminant clinical course in our patient, this modality of treatment was administered to make sure that the antibiotics reached the affected area.

As brain abscesses occur frequently, a high index of suspicion and an early CT scan of head may help with management. Recommendations vary regarding the treatment of brain abscesses in infancy. Multiple abscesses and inadequate response to medical measures require repeated aspiration and drainage [11]. These procedures were used in our patient, along with continued medical management. However, even with these aggressive measures, the morbidity of this disease remains high, and mortality is about $30 \%$ to $50 \%$ [1].

Isolation of an atypical organism should alert the physician to carefully evaluate the patient for predisposing factors, like presacral sinuses, spinal defects, immunodeficiencies and CSF leaks. Prompt epidemiological surveillance and ensuring strict adherence to aseptic techniques are essential to control the source and prevent epidemics. Non-availability of appropriate bacteriological techniques, coupled with probable under-reporting by clinicians, have led to a lack of credible data regarding the diagnosis and management of meningitis caused by atypical organisms in the developing countries.

\section{Acknowledgements}

Financial support was provided by NIL.

\section{References}

1. Graham D.R., Band J.D. Citrobacter diversus brain abscess and meningitis in neonates. JAMA 1981;245:1923-5.

2. Gwynn C.M., George R.H. Neonatal Citrobacter meningitis. Arch Dis Child 1973;48:455-78.

3. Kline M.W., Kaplan S.L., Hawkins E.P., Mason E.O. Pathogenesis of brain abscess formation in an infant rat model of Citrobacter diversus bacteremia and meningitis. J Infect Dis 1988; 157:106-12.

4. Levine R.S., Rosenberg H.K., Zimmerman R.A., Stanford A.N. Complications of Citrobacter neonatal meningitis : Assessment by real time cranial sonography correlated with CT. Am J Neuroradiol 1983;4:668-71.

5. Gross R.J., Rowe B., Easton J.A. Neonatal meningitis caused by Citrobacter koseri. J Clin Pathol 1973;26:138-9.

6. Eppes S.C., Woods C.R., Mayer A.S., Klein J.D. Recurring ventriculitis due to Citrobacter diversus: Clinical and bacteriologic analysis. Clin Infect Dis 1993;17:437-40. 
7. Gross R.J., Rowe B. An extended antigenic scheme for Citrobacter koseri. Journal of Hygiene 1975;75:121-7.

8. Lipsky B.A., Hook E.W., Smith A.A. Citrobacter infections in humans: Experience at the Seattle Veterans Administration Medical Center and a review of literature. Rev Infect Dis 1980;2:746-60.

9. Nelson J.D., Bradley S.J. Preferred therapy for specific bacterial and viral pathogens. In: Nelson's pocket book of pediatric antimicrobial therapy, 14 th Ed, Lippincott Williams \& Wilkins, Philadelphia, 2000:44-55.

10. McCracken G.H. Jr., Mize S.G., Threlkeld N. Intraventricular gentamicin therapy in Gram-negative bacillary meningitis of infancy. Report of the Second Neonatal Meningitis Cooperative Study Group. Lancet 1980; $12: 787-91$

11. Klein J.O., Marcy S.M. Bacterial sepsis and meningitis. In : Remington and Klein (Eds). Infectious diseases of the fetus and newborn infant, $4^{\text {th }}$ Ed, WB Saunders Co., Philadelphia, 1995:835-90.

12. Jadavji T., Humphreys R.P., Prober C.G. Brain abscesses in infants and children. Ped Infect Dis J 1985;4:394-8. 